\title{
CONGENITAL ABSENCE OF THE TRACHEA
}

\section{BY}

\author{
I. KESSEL AND J. N. SMITH \\ From the Departments of Paediatrics and Surgery, University of the Witwatersrand, and the Queen Victoria \\ Maternity Hospital, Johannesburg, South Africa
}

(RECEIVED FOR PUblication MARCH 16, 1953)

In 1941 Wolman reviewed the data of 11 cases of congenital stenosis of the trachea and recorded one of his own. One of these cases was a stillborn child; seven of the live-born infants died under the age of 6 months. Gruber (1870) recorded the details of the stillborn case. Finkelstein (1924) described the case, cited by Wolman, where death took place at the age of 4 days; in this infant the lumen of the trachea was the size of a pencil lead. In such cases the trachea may be narrowed throughout its length or only for a short segment of $1-2 \mathrm{~cm}$. The case recorded here showed complete absence of the trachea. Discussing the development of the lungs, Snyder and Rosenfeld (1937a and b) believed that intrauterine respiratory movements play a major role in this development, aiding the dilatation of the alveoli. Each alveolus of foetal lung has a lumen, which is not obliterated ; fluid is present in this lumen and its source has been the subject of much discussion. Snyder and Rosenfeld believed its source was from the aspiration of the media in which the foetus is immersed, and is necessary for normal development. However, Potter and Bohlender (1941) have reported two unusual abnormalities of the respiratory system which indicated that the inflow and outflow of amniotic fluid in the foetal respiratory tract is not essential for normal alveolar development. These malformations indicated that the fluid in the foetal alveoli can be a transudation of body fluid through the alveolar walls, and that normal lung development may occur without the inflow of amniotic fluid. One of Potter and Bohlender's cases had a malformation of the cricoid cartilage producing the respiratory obstruction. The lungs in this case were normal histologically with normal alveolar development.

\section{CASE REPORT}

In September, 1952, a woman aged 22 years gave birth to a full-term male infant weighing $6 \mathrm{lb}$. $6 \mathrm{oz}$. and measuring 21 in. in length. She had had one miscarriage previously. Her blood group was $\mathrm{A}$, and she was Rh positive. Her blood Wassermann reaction was negative. The pregnancy was normal except that $\mathscr{O}$ she developed hydramnios. At the beginning of $O$ pregnancy her weight was $136 \mathrm{lb}$., and this increased to $167 \frac{1}{2} \mathrm{lb}$. at full-term. A radiograph of the pelvis and abdomen showed a single foetus, and the shape of the pelvis was anthropoid. The foetal heart was regular and strong, and its rate during the second stage of labour varied between 130 and 150 per minute. The membranes ruptured 38 hours before the end of the second stage of labour. The child was born as a normal vertex delivery. After delivery of the head thick, offensive liquor drained away. The placenta was ovoid in shape and very calcified; the vessels were exceptionally large and the insertion was velamentous. The umbilical cord was only 11 in. in length. The child was quite pink at birth; the air passages were cleared and attempts at breathing were made. Lobeline and vitamin $\mathrm{K}$ were administered, and the infant placed in an oxygen tent. $\mathrm{He}$ became cyanosed, and this cyanosis increased despite the oxygen atmosphere. The child died an hour and six minutes after birth.

NECROPSY Findings.-The body was that of a fullterm male infant weighing $6 \mathrm{lb} .6 \mathrm{oz}$. and with a crownheel measurement of 21 in. There was no jaundice or oedema. The thymus gland was normal. The larynx was normal but ended blindly below the level of the cricoid cartilage. The vocal cords were normal. There was no trachea. The right and left bronchi were normal and were fused in the midline. A fistulous opening was present about $1 \mathrm{~mm}$. below the upper border of the fusion of the bronchi, and there was a fistulous communication between the bronchi and the oesophagus (Figs. 1, 2, and 3). The lungs were normal in size, but were airless except for some parts of both upper lobes. Numerous subpleural haemorrhages were present. The heart muscle was firm, and there was no evidence of any congenital abnormality. There were numerous small fresh subepicardial haemorrhages, and petechiae. The liver weighed $150 \mathrm{~g}$. and was very congested; the gallbladder was normal. The spleen was of average size and congested. The kidneys weighed $26 \mathrm{~g}$., and their capsules stripped easily, leaving a smooth surface; they also were congested. The pituitary, thymus, thyroid, and suprarenal glands were all normal. The oesophagus was normal except for the 
FIG. 1.-Photograph of the specimen showing the oesophagus with the fistulous opening, illustrating its position in relation to the lungs.

Fig. 2.-Photograph of the necropsy specimen showing the oesophagus with two probes placed in position to illustrate, first the fistulous opening above, and second the position of the oesophagus at the diaphragmatic level.

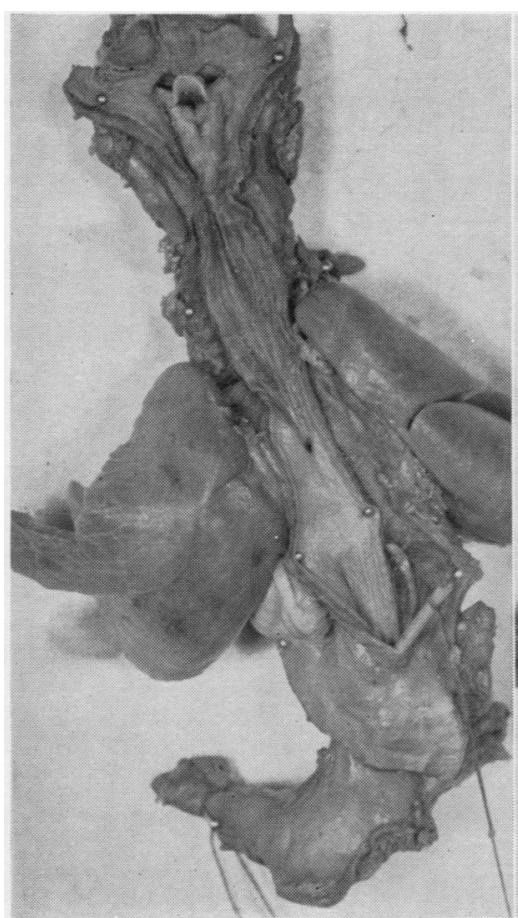

Fig. 1

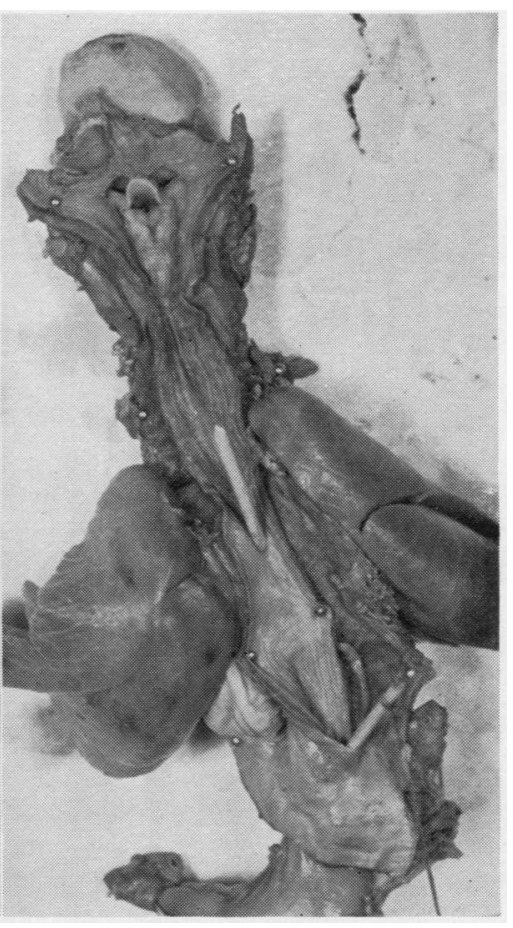

FiG. 2

Fig. 3.-A drawing to illustrate the fistulous communication between the oesophagus and the bronchi.

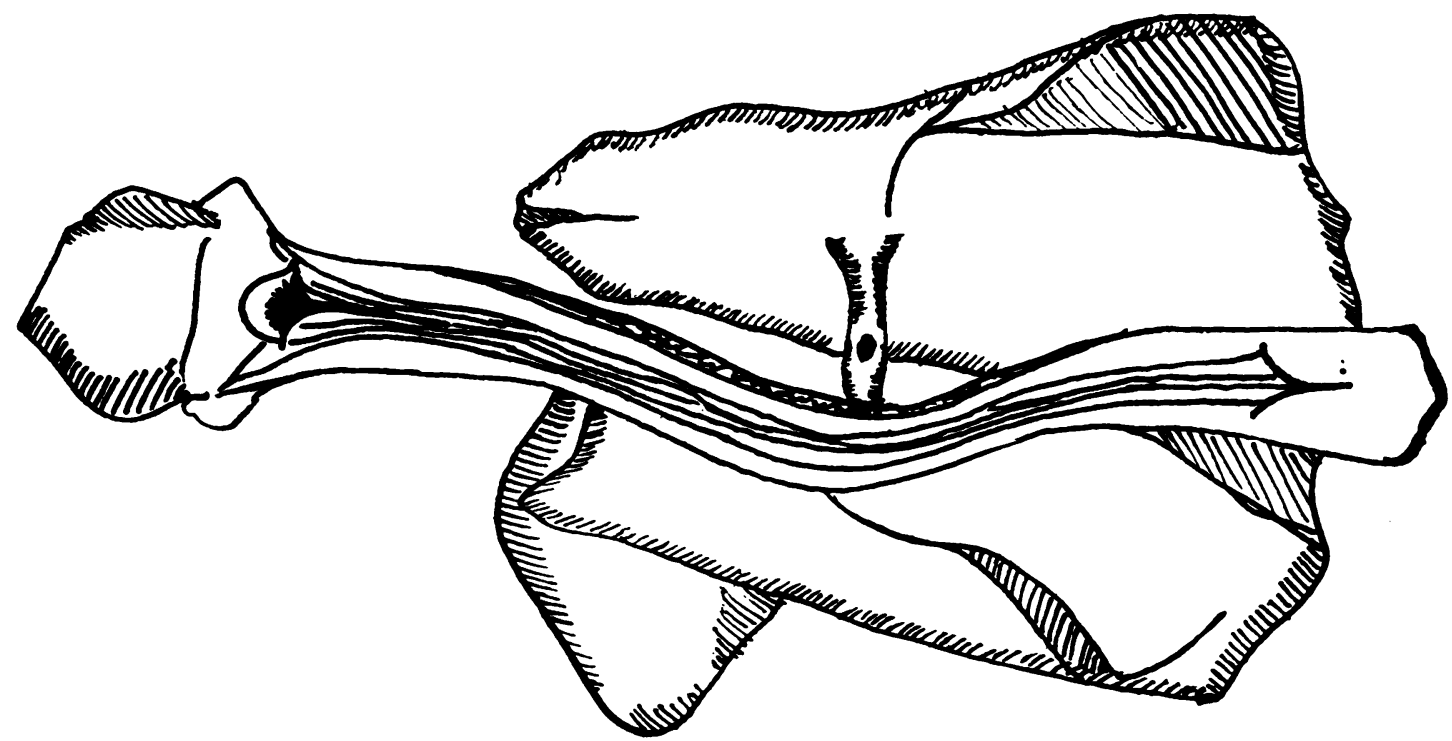


fistula communicating with the bronchi (Figs. 1, 2, and 3). The stomach and bowel were normal. The pancreas was congested. The brain was congested and oedematous. Histological examination of a section of a specimen from the lung showed extreme congestion, focal oedema, and some extravasation of red cells into the alveolar spaces; in addition, there were large areas of atelectasis. Sections of specimens from the liver, spleen, pancreas, kidney, and suprarenals all showed congestion.

\section{Discussion}

This infant gradually expired an hour and a few minutes after birth, and did not at any time show an adequate respiratory function. The pregnancy was associated with hydramnios. At necropsy the lungs showed some slight degree of aeration in the upper lobes. This aeration took place during life via the fistulous communication between the oesophagus and bronchi in the complete absence of the trachea. In this case there could not have been much, if any, inflow and outflow of amniotic fluid in the foetal respiratory system, but the lung development was normal. Morison (1949) has reported congenital malformations in one of a monozygotic twin ; this stillborn foetus had multiple anomalies including complete atresia of the trachea and oesophagus. It was suggested that the malformations were due to a "non-specific influence causing an arrest of development of those structures whose formation might be in a critical stage." Our case showed complete absence of the trachea with a fistulous communication between the oesophagus and trachea.

\section{SUMMARY}

ต

A case of complete absence of the trachea in $a \vec{\circ}$ full-term male live-born child is reported; death $\vec{\omega}$ occurred an hour and a few minutes after birth. A broncho-oesophageal fistula was present and the $\vec{x}$ lungs showed normal development. Hydramniosio was present during pregnancy. No previous report of a similar abnormality has been found in theo literature.

The authors wish to thank Dr. K. F. Mills, Medical Superintendent, for permission to publish this case. They are also indebted to Professor O. S. Heyns and Dr. L. G. R. Van Dongen for allowing access to this case. Finally, they wish to thank Mr. A. M. Shevitz for the photographs, and Mr. N. Oelofse for his drawing.

REFERENCES
Finkelstein, H. (1924). Lehrbuch der Säuglingkrankheiten, 3rd ed., p. 621. Springer, Berlin.

Gruber, W. (1870). Ost. Z. prakt. Heilk. 16, 7. Cited by Haardt, W. (1938). Wien. klin. Wschr., 51, 657,

Morison, J. E. (1949). Arch. Dis. Childh., 24, 214.

Potter, E. L., and Bohlender, G. P. (1941). Amer. J. Obstet. Gynec. 42, 14

nyder, F. F., and Rosenfeld, M. (1937a). J. Amer. med. Ass., 108 1946.

Wolman (1937b). Proc. Soc. exp. Biol., N.Y., 36, 45.

Wolman, I. J. (1941). Amer. J. Dis. Child., 61, 1263. 